\section{Takayasu Arteritis and Pregnancy from the Point of View of the Internist}

\section{To the Editor:}

Takayasu's arteritis (TA) usually affects young women of childbearing age, sometimes coinciding with pregnancy. Both incidence and clinical expression are different depending on the geographic area, probably because of different HLA antigens associated ${ }^{1,2}$. Some observational studies attribute a better prognosis in Western patients ${ }^{3}$. Only a few Caucasian cases of TA and pregnancy have been published. We describe the clinical and epidemiological features of 4 successful deliveries in 3 patients with TA, underlining the most important data from the internist's point of view.

Case 1. A 22-year-old Caucasian woman was admitted because of malaise during the last 4 months and inflammatory back pain. At examination, blood pressure was $125 / 80 \mathrm{~mm} \mathrm{Hg}$, all pulses were symmetrically palpable, and an epigastric bruit was heard. Routine blood components showed hemoglobin 9'4 g/dl, mutated citrullinated vimentin antibodies (MCV) 76, and erythrocyte sedimentation rate (ESR) $150 \mathrm{~mm} / \mathrm{h}$. An arteriography demonstrated stenosis of abdominal aorta, including both renal arteries as well as mesenteric artery. Carotid artery was also affected (Figure 1A). She was diagnosed with $\mathrm{TA}$, and prednisone $(1 \mathrm{mg} / \mathrm{kg})$ was started and then progressively tapered, with a progressive extinction of the symptoms and normalization of acute reactants.

A maintenance dose of $5 \mathrm{mg} /$ day was prescribed when the patient became pregnant 7 years later. At 24th week of gestation she was diagnosed with gestational diabetes mellitus, and insulin therapy was started, with good response. No other complications followed until the 35th week, when membranes ruptured. As a result of severe fetal bradycardia a cesarean section was performed. A healthy boy of $1870 \mathrm{~g}$ was born. Apgar test scored 10 points. The patient became pregnant again 2 years later. She was again diagnosed with gestational diabetes. Cesarean section was elected again and a girl was born at the 35th week. She weighed $2450 \mathrm{~g}$ and had a normal size. The baby received phototherapy because of jaundice, without any other complication.

Case 2. A 36-year-old Caucasian woman with 1 previous normal gestation became pregnant. After 38 weeks, labor was induced by cesarean section, because of previous placenta. Two univitelline fetusus of 2400 and $2500 \mathrm{~g}$ were successfully delivered and puerperium was uncomplicated until 10 days later, when slight fever appeared. All the peripheral pulses were present and symmetric. Routine hematological and chemical components showed hemoglobin 8'7 g/dl, MCV 80, white-cell count $11,200 / \mu 1$, platelets $695,000 / \mu 1$, ESR $120 \mathrm{~mm} / \mathrm{h}$, and C-reactive protein (CRP) 113 $\mathrm{mg} / \mathrm{l}$. A computed tomography (CT) scan demonstrated a wide aorta aneurysm (16 cm in diameter) from renal arteries to iliac bifurcation. The left renal artery was included, and a mural thrombus could be seen. There was also an aneurysm in the left subclavian artery, a right primitive carotid stenosis, and left internal carotid stenosis (Figure 1B). A diagnosis of TA was then established. The abdominal aneurysm was removed, and a Dacron prosthesis was implanted. Biopsy of the excised material showed arteritis with hystiocytes, plasmatic cells, and lymphocytes. Prednisone 1 $\mathrm{mg} / \mathrm{kg} / \mathrm{day}$ was started and afterwards tapered, with improvement of the analytic and clinical measures.

Case 3. A 29-year-old Caucasian woman was admitted because of 2-month history of malaise, headache, and high blood pressure (190/120 mm Hg). Examination showed weak pulses in both radial arteries, while the rest was normal. Routine hematological and chemical blood components were normal and abdominal Doppler scan showed a small right kidney with a probable stenosis in the renal artery. A digital intravenous arteriography subtraction (DIVAS) scan demonstrated a stenosis in the infrarrenal aorta, both primitive iliac arteries, and inferior mesenteric artery. Right renal artery was not visible (Figure 1C). The patient was treated with angiotensin-converting enzyme inhibitors in order to normalize blood pressure. No immunosuppressive treatment was started.

One year later, she became pregnant. During gestation she had preeclampsia as a complication, and was treated with atenolol and methyldopa. At the 38th week of gestation, cesarean section was performed because of growth retardation. The newborn girl's weight was $2065 \mathrm{~g}$ and initial Apgar test was 9/10. She developed respiratory distress and neonatal sepsis was suspected. Antibiotic therapy was maintained for 7 days until all cultures were negative. The baby also presented jaundice, which was treated with phototherapy. There were no more complications.

It must be pointed out that all 4 pregnancies were successful. However, they all finished with cesarean section and some complications such as gestational diabetes and preeclampsia were observed. No newborns, except 1 with intrauterine growth retardation, respiratory distress, and abnormal jaundice, had any complication attributable to the mother's disease.

Among the previous reported cases of TA and pregnancy (Table 1), most of them among Asian women, a significant incidence of abortions is noted $(15 \%)$, although the majority were uncomplicated pregnancies and deliveries. Only 1 neonatal death is described. Eight percent of the newborns were premature and low birth weight was a frequent situation (15\%). Preeclampsia/high blood pressure were observed in a large proportion of patients (39\%). Exacerbation of the disease during pregnancy has been mentioned ${ }^{8}$, but it is not the rule. In contrast, it has been pointed out that a higher frequency of cardiovascular events might be seen ${ }^{7}$. Cesarean section was performed in only $23 \%$ of cases in the literature. Thus, it is not systematically recommended ${ }^{5}$. Regarding our patients, it was always performed because of gynecologic indication and not because of TA per se.

High blood pressure in the late gestational period, abdominal and renal involvement, disease activity during the early pregnancy, and delay in medical attention are described as some of the predictor factors of a bad outcome $^{4-6}$. The lowest possible dose of corticosteroids to control the dis-

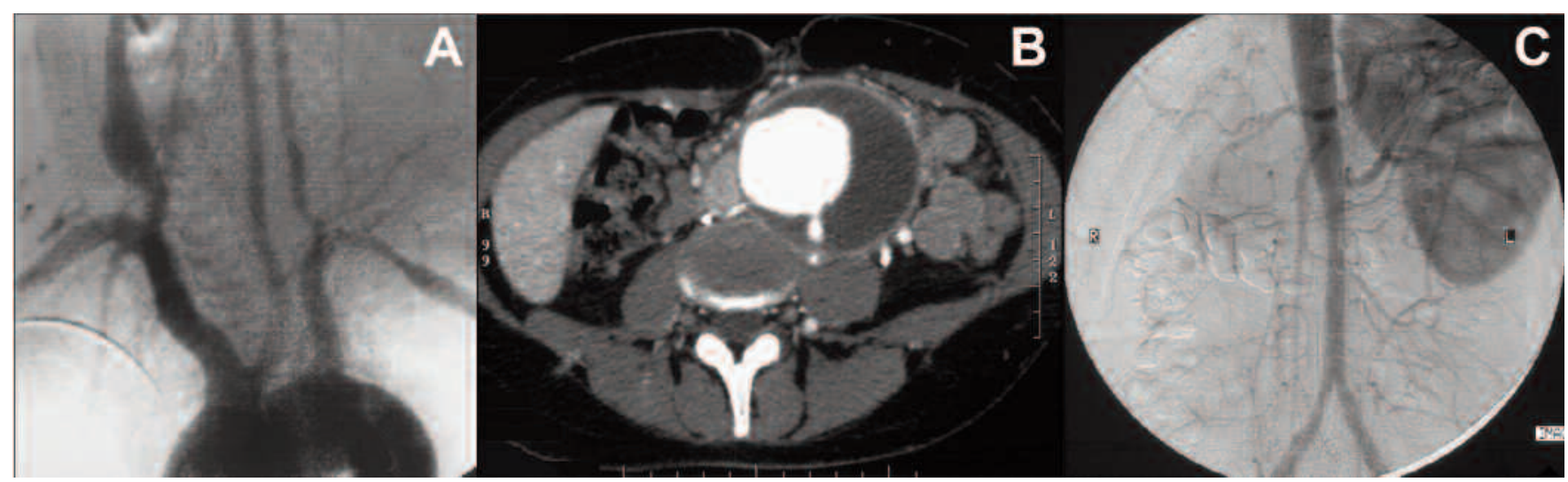

Figure 1. A. Case 1: arteriography showing affected carotid artery. B. Case 2: CT: aorta aneurysm. C: Case 3: DIVAS scan showing stenosis in infrarenal aorta, both primitive iliac arteries, and inferior mesenteric artery. Right renal artery not visible. 
Table 1. Takayasu arteritis and pregnancy series.

\begin{tabular}{|c|c|c|c|c|c|c|c|c|c|c|}
\hline & $\mathrm{n}$ & $\begin{array}{c}\text { Preeclampsia/ } \\
\text { HBP }\end{array}$ & LHF & $\begin{array}{l}\text { Postpartum } \\
\text { Septicemia }\end{array}$ & $\begin{array}{l}\text { Maternal } \\
\text { Death }\end{array}$ & $\begin{array}{l}\text { IUGR/Low } \\
\text { Birth Weight }\end{array}$ & Prematurity & $\begin{array}{l}\text { Abortion/ } \\
\text { Intrauterine } \\
\text { Death }\end{array}$ & $\begin{array}{c}\text { Neonatal } \\
\text { Deaths }\end{array}$ & $\begin{array}{c}\text { Cesarean } \\
\text { Section }\end{array}$ \\
\hline Sharma $^{5}$ & 24 & 11 & 2 & 1 & 0 & 5 & 4 & 7 & 0 & 1 \\
\hline Wong ${ }^{6}$ & 30 & 11 & 0 & 0 & 0 & 9 & 1 & 4 & 1 & 4 \\
\hline Ishikawa $^{7}$ & 33 & 15 & 2 & 1 & 0 & 4 & 2 & 2 & 0 & 10 \\
\hline Total $(\%)$ & 137 & $54(39)$ & $5(4)$ & $2(1)$ & 0 & $20(15)$ & $11(8)$ & $20(15)$ & $1(0.7)$ & $31(23)$ \\
\hline
\end{tabular}

n: Total number of pregnancies; HBP: high blood pressure; IUGR: intrauterine growth retardation; NA: not applicable; LHF: left heart failure.

ease is recommended. Azathioprine, which seems to be one of the safest immunosuppressive options, although associated with prematurity, should be considered in the few cases that might not respond to corticosteroids. Other therapies usually employed in TA, such as methotrexate, are forbidden in pregnancy. Therefore, their use must be accompanied by effective contraceptive measures ${ }^{10}$.

TA is not a major contraindication for pregnancy in either Caucasian or Asian patients, as long as the disease is clinically stable ${ }^{11}$. According to previous experience, the disease does not worsen because of pregnancy ${ }^{7}$, although it conveys substantial morbidity. Thus, it requires careful control by a multidisciplinary team with close monitoring of pregnancy and special attention to blood pressure.

ORIOL GASCH, MD; ANTONIO VIDALLER, PhD; RAMON PUJOL, PhD, Internal Medicine Service, Hospital de Bellvitge, Barcelona, Spain. Address reprint requests to Dr. Gasch. E-mail: urigasch@hotmail.com

\section{REFERENCES}

1. Cid MC, Font C, Coll-Vinent B, Grau JM. Large vessel vasculitides. Curr Opin Rheumatol 1998;10:18.

2. Moriuchi J, Wakisaka A, Aizawa M, et al. HLA-linked susceptibility gene of Takayasu disease. Human Immunol
1982;87:91

3. Sabba C, Pugliese D, Caruso G, et al. Takayasu's arteritis. Am J Cardiovasc Pathol 1990;3:95-9.

4. Aso T, Abe S, Yaguchi T. Clinical gynecologic features of pregnancy in Takayasu arteritis. Heart Vessels 1992;7:125-32.

5. Sharma BK, Jain S, Vasistha K. Outcome of pregnancy in Takayasu arteritis. Int J Cardiol 2000;75:S159-62.

6. Wong V, Wang R. Pregnancy and Takayasu's arteritis. Am J Med 1982;75:597-601

7. Ishikawa K, Matsuura S. Occlusive thromboaortopathy (Takayasu's disease) and pregnancy. Am J Cardiol 1982;50:1293-9.

8. Kerr GS, Hallahan CW, Giordano J, et al. Takayasu arteritis. Ann Intern Med 1994;120:919-29.

9. Matsumura A, Moriwaki R, Numano F. Pregnancy in Takayasu arteritis from the view of internal medicine. Heart Vessels 1992;7:120-4

10. Langford CA, Kerr GS. Pregnancy in vasculitis. Curr Opin Rheumatol 2002;14:36-41.

11. Seo P. Pregnancy and vasculitis. Rheum Dis Clin North Am 2007:33:299-317

J Rheumatol 2009;36:7; doi:10.3899/jrheum.080362 